\title{
Effects of Supplemental Perioperative Oxygen in Preventing Transient Hypoparathyroidism After Total Thyroidectomy
}

Sajjid Mehmood ${ }^{1}$, Mehwish Changeez ${ }^{1}$, Munazzah Aziz ${ }^{1}$, Naqqash Adnan ${ }^{1}$, Maham Tariq ${ }^{1}$, Sara Malik ${ }^{1}$, Jahangir S. Khan ${ }^{1}$

1. Surgery, Holy Family Hospital, Rawalpindi, PAK

$\square$ Corresponding author: Mehwish Changeez, mehwishchangez@gmail.com Disclosures can be found in Additional Information at the end of the article

\section{Abstract}

\section{Background}

Thyroidectomy is one of the most common endocrine procedures performed worldwide. Postoperative hypocalcemia is a troublesome complication of thyroid surgery. Few studies have considered the role of supplemental oxygen in preventing postoperative hypocalcemia in patients undergoing thyroidectomy.

\section{Materials and methods}

This was a randomized controlled study comparing the use of high flow supplemental oxygen $\left(\mathrm{FiO}_{2} 80 \%\right)$ with low flow oxygen $\left(\mathrm{FiO}_{2} 30 \%\right)$ in preventing transient postoperative hypocalcemia. Seventy-eight patients undergoing thyroidectomy during the year 2017 in Surgery Unit-1, Holy Family Hospital were included in the study.

\section{Results}

Transient hypoparathyroidism was present in $20.5 \%(n=8 / 39)$ in group 1 while it was present in $59.0 \%(n=23 / 39)$ in group 2 patients. Patients in group $1\left(\mathrm{FiO}_{2} 80 \%\right)$ demonstrated a significantly lower percentage of transient hypoparathyroidism than group $2\left(\mathrm{FiO}_{2} 30 \%\right)$ $(\mathrm{P}=0.001)$.

\section{Conclusion}

Received 08/31/2018 Review began 09/24/2018 Review ended 09/25/2018 Published 10/11/2018

\section{(c) Copyright 2018}

Mehmood et al. This is an open access article distributed under the terms of the Creative Commons Attribution License CC-BY 3.0., which permits unrestricted use, distribution, and reproduction in any medium, provided the original author and source are credited.
Our study concluded that high flow supplemental oxygen $\left(\mathrm{FiO}_{2} 80 \%\right)$ significantly decreases the risk of developing postoperative transient hypocalcemia.

Categories: Endocrinology/Diabetes/Metabolism, General Surgery

Keywords: hypoparathyroidism, hypocalcemia, supplemental oxygen

\section{Introduction}

For thyroid disorders, thyroid lobectomy or total thyroidectomy is a commonly accepted surgical treatment. Two well-known complications of thyroid surgery are hypoparathyroidism and dysfunction of the recurrent laryngeal nerve (RLN). The complication

How to cite this article

Mehmood S, Changeez M, Aziz M, et al. (October 11, 2018) Effects of Supplemental Perioperative Oxygen in Preventing Transient Hypoparathyroidism After Total Thyroidectomy. Cureus 10(10): e3440. DOI 10.7759 /cureus. 3440 
rate varies for both permanent hypoparathyroidism (1\% to $11 \%$ ) and RLN injury (0\% to $14 \%$ ) [1]. The rate of unintentional excision of the parathyroid gland may be as high as $9 \%$, as the identification of the parathyroid during thyroid surgery can be difficult, even for experienced surgeons. The incidence of transient hypoparathyroidism after total thyroidectomy range from $5 \%$ to $60 \%$ [2]. Mechanical damage, devascularization, or removal during surgery can be the cause of postoperative hypoparathyroidism [3]. Damage to the parathyroid glands during thyroid surgery can affect the quality of life of patients. Postoperative hypocalcemia may be asymptomatic or present with a range of symptoms such as tetany, perioral numbness, muscle cramps, and a tingling sensation in the hands. Acute hypocalcemia can cause life-threatening cardiovascular accidents like torsades de pointes, heart blocks, hypocalcemic cardiomyopathy, and heart failure [4].

Prior to the induction of anesthesia, $100 \% \mathrm{O}_{2}$ administration increases the margin of safety during intubation [5]. The availability of molecular oxygen to tissues is increased by hyperoxia, that is, by increasing dissolved oxygen in plasma [6]. Recently, the new trend of highconcentration supplemental perioperative oxygen to increase tissue oxygenation is being used and thus improves postoperative outcome. Perioperative supplemental $\mathrm{O}_{2}$ provides adequate tissue oxygenation and improves outcomes by preventing the vicious spiral triggered by hypoxemia [7]. Oxygen is considered a drug and must be prescribed and administered for specific indications [8]. High-concentration supplemental perioperative oxygen prevents vasospasms and thus hypoxia, decreasing the incidence of biochemical hypoparathyroidism [9].

Various studies have been conducted on the effect of supplemental oxygen administration on the development of surgical site infection [10]. However, there are very few studies that have observed the role of oxygen in preventing biochemical hypocalcemia. A study conducted by Schietroma $\mathrm{M}$ et al. showed that high-concentration supplemental perioperative oxygen during thyroid surgery and for six postoperative hours is effective in reducing postoperative transient biochemical hypoparathyroidism. It occurred less frequently with the high concentration supplemental perioperative oxygen group $\left(\mathrm{FiO}_{2} 80 \%\right)$, i.e., $16.3 \%$ as compared to the control group (those receiving low supplemental perioperative oxygen $\mathrm{FiO}_{2} 30 \%$ ), i.e., $48.5 \%$ [9].

Therefore, the rationale of this study is to measure the effect of the new trend of the high concentration supplemental perioperative oxygen on the frequency of transient biochemical hypoparathyroidism after thyroid surgery with the standard concentration of oxygen used during thyroid surgery and to compare it with international studies and, if found beneficial, to take it into consideration for routine use in practice.

\section{Materials And Methods}

This randomized control study was conducted from January 2017 to December 2017 in Surgery Unit-1, Holy Family Hospital, Rawalpindi. The study included all patients undergoing elective thyroid surgery. Patients aged over 75 years and with a previous history of renal, hepatic, or immunological diseases were excluded from the study. Patients with a history of alcohol or drug abuse were also excluded.

The study was undertaken after approval from the Hospital Ethical Committee. All patients fulfilling the above-mentioned selection criteria were included in the study. After admission, written informed consent was taken for participation in the research project. All patients received information regarding perioperative hyperoxia and how it will be used and its risks and benefits from trained post-graduate trainees. Patients were allocated into two groups via the simple random sampling technique through a random number list generated by SPSS 22 (IBM Corp., Armonk, NY, US). Total thyroidectomy was performed by consultant surgeons of Surgery Unit-1 at Holy Family Hospital. The postoperative course was monitored by sending 


\section{Cureus}

serum calcium levels at 24, 48, and 72 hours in the postoperative period. Group 1 received $\mathrm{FiO}_{2} 80 \%$ during the operation and six hours after the operation period via an inbreathing face mask while Group2 received $\mathrm{FiO}_{2} 30 \%$ during operation and six hours after the operation via an inbreathing face mask.

All data were entered and analyzed using SPSS 22. Descriptive statistics were used to measure qualitative and quantitative variables. For all qualitative variables like gender and the presence or absence of transient hypoparathyroidism, frequencies along with percentages were calculated. For continuous variables like age and serum calcium levels, the mean along with standard deviation was calculated. To compare the proportion of patients with transient biochemical hypoparathyroidism of both study groups, Pearson's chi-square test at a $5 \%$ level of significance was applied. A p-value less than 0.05 was considered statistically significant.

\section{Results}

A total of 78 patients between the ages of 18 and 75 years, irrespective of gender, undergoing elective thyroid surgery (total thyroidectomy) were enrolled in the study. All the patients were equally distributed into two groups. Group 1 received $\mathrm{FiO}_{2} 80 \%$ while Group 2 received $\mathrm{FiO}_{2} 30 \%$ during the operation and six hours after the operation via an inbreathing face. Serum calcium at 24,48 , and 72 hours was estimated in each patient of both groups. Gender and age distribution are recorded in Tables 1-2.

\begin{tabular}{|c|c|c|}
\hline \multirow{2}{*}{ Gender } & \multicolumn{2}{|c|}{ Study groups } \\
\hline & $\mathrm{FiO}_{2} 80 \%$ & $\mathrm{FiO}_{2} 30 \%$ \\
\hline \multirow{2}{*}{ Males } & 13 & 12 \\
\hline & $33.3 \%$ & $30.8 \%$ \\
\hline \multirow{2}{*}{ Females } & 26 & 27 \\
\hline & $66.7 \%$ & $69.2 \%$ \\
\hline \multirow[t]{2}{*}{ Total } & 39 & 39 \\
\hline & $100.0 \%$ & $100.0 \%$ \\
\hline
\end{tabular}

TABLE 1: Demographic profile of the study population (age distribution) 


\section{Cureus}

\begin{tabular}{|c|c|c|c|}
\hline Study groups & Gender & Mean age (years) & SD \\
\hline \multirow{3}{*}{$\mathrm{FiO}_{2} 80 \%$} & Males & 42.7 & 13.4 \\
\hline & Females & 36.4 & 15.8 \\
\hline & Total & 38.5 & 15.2 \\
\hline \multirow{3}{*}{$\mathrm{FiO}_{2} 30 \%$} & Males & 33.1 & 12.7 \\
\hline & Females & 37.4 & 18.1 \\
\hline & Total & 36.1 & 16.6 \\
\hline
\end{tabular}

TABLE 2: Mean serum calcium at 24,48 , and 72 hours after surgery

Mean serum calcium levels (mg/dl) in both the groups at 24,48 , and 72 hours are recorded in Table 3. Transient hypoparathyroidism was present in $20.5 \%(n=8 / 39)$ in Group 1 while it was present in 59.0\% ( $\mathrm{n}=23 / 39)$ in Group 2 patients. Patients in Group $1\left(\mathrm{FiO}_{2} 80 \%\right)$ demonstrated a significantly lower percentage of transient hypoparathyroidism than Group $2\left(\mathrm{FiO}_{2} 30 \%\right)$ $(\mathrm{P}=0.001)$. Results are recorded in Table 4 .

\begin{tabular}{|c|c|c|c|c|}
\hline \multicolumn{2}{|c|}{ Study groups } & \multicolumn{3}{|c|}{ Serum calcium (mg/dl) } \\
\hline & & 24 hours & 48 hours & 72 hours \\
\hline \multirow{2}{*}{$\mathrm{FIO}_{2} 80 \%$} & Mean & 9.13 & 9.48 & 9.30 \\
\hline & SD & 0.57 & 0.71 & 0.49 \\
\hline \multirow{2}{*}{$\mathrm{FIO}_{2} 30 \%$} & Mean & 9.20 & 8.86 & 9.37 \\
\hline & SD & 0.81 & 0.77 & 0.781 \\
\hline
\end{tabular}

TABLE 3: Perioperative transient hypoparathyroidism in both groups 


\section{Cureus}

\begin{tabular}{|c|c|c|c|c|}
\hline \multirow{2}{*}{ Transient hypoparathyroidism } & \multicolumn{2}{|c|}{ Study groups } & \multirow{2}{*}{ Total } & \multirow{2}{*}{ p-value chi-square } \\
\hline & $\mathrm{FiO}_{2} 80 \%$ & $\mathrm{FiO}_{2} 30 \%$ & & \\
\hline \multirow{2}{*}{ Present } & 8 & 23 & 31 & \multirow{6}{*}{0.001} \\
\hline & $20.5 \%$ & $59.0 \%$ & $39.7 \%$ & \\
\hline \multirow{2}{*}{ Absent } & 31 & 16 & 47 & \\
\hline & $79.5 \%$ & $41.0 \%$ & $60.3 \%$ & \\
\hline \multirow[t]{2}{*}{ Total } & 39 & 39 & 78 & \\
\hline & $100.0 \%$ & $100.0 \%$ & $100.0 \%$ & \\
\hline
\end{tabular}

TABLE 4: Gender-based stratification in both groups (males)

Stratification with respect to gender (Tables 5-6) and age (Tables 7-8), showed similar trends. The p-value was found to be $<0.05$ in all cases, implying that patients in Group 1 (FiO2 80\%) demonstrated a significantly lower percentage of transient hypoparathyroidism than Group 2 (FiO2 30\%) when stratified for effect modifiers.

\begin{tabular}{|c|c|c|c|c|}
\hline \multirow{2}{*}{ Transient Hypoparathyroidism } & \multicolumn{2}{|c|}{ Study groups } & \multirow{2}{*}{ Total } & \multirow{2}{*}{ p-value chi-square } \\
\hline & $\mathrm{FiO}_{2} 80 \%$ & $\mathrm{FiO}_{2} 30 \%$ & & \\
\hline \multirow{2}{*}{ Present } & 1 & 5 & 6 & \multirow{6}{*}{0.047} \\
\hline & $7.7 \%$ & $41.7 \%$ & $24.0 \%$ & \\
\hline \multirow{2}{*}{ Absent } & 12 & 7 & 19 & \\
\hline & $92.3 \%$ & $58.3 \%$ & $76.0 \%$ & \\
\hline \multirow[t]{2}{*}{ Total } & 13 & 12 & 25 & \\
\hline & $100.0 \%$ & $100.0 \%$ & $100.0 \%$ & \\
\hline
\end{tabular}

TABLE 5: Gender-based stratification in both groups (females) 


\section{Cureus}

\begin{tabular}{|c|c|c|c|c|}
\hline \multirow{2}{*}{ Transient Hypoparathyroidism } & \multicolumn{2}{|c|}{ Study groups } & \multirow{2}{*}{ Total } & \multirow{2}{*}{ p-value chi-square } \\
\hline & $\mathrm{FIO}_{2} 80 \%$ & $\mathrm{FIO}_{2} 30 \%$ & & \\
\hline \multirow{2}{*}{ Present } & 7 & 18 & 25 & \multirow{6}{*}{0.004} \\
\hline & $26.9 \%$ & $66.7 \%$ & $47.2 \%$ & \\
\hline \multirow{2}{*}{ Absent } & 19 & 9 & 28 & \\
\hline & $73.1 \%$ & $33.3 \%$ & $52.8 \%$ & \\
\hline \multirow[t]{2}{*}{ Total } & 26 & 27 & 53 & \\
\hline & $100.0 \%$ & $100.0 \%$ & $100.0 \%$ & \\
\hline
\end{tabular}

TABLE 6: Demographic profile of the study population (gender distribution)

\begin{tabular}{|c|c|c|c|c|}
\hline \multirow{2}{*}{ Transient Hypoparathyroidism } & \multicolumn{2}{|c|}{ Study groups } & \multirow{2}{*}{ Total } & \multirow{2}{*}{$p$-value chi-square } \\
\hline & $\mathrm{FiO}_{2} 80 \%$ & $\mathrm{FiO}_{2} 30 \%$ & & \\
\hline \multirow{2}{*}{ Present } & 7 & 17 & 24 & \multirow{6}{*}{0.003} \\
\hline & $24.1 \%$ & $63.0 \%$ & $42.9 \%$ & \\
\hline \multirow{2}{*}{ Absent } & 22 & 10 & 32 & \\
\hline & $75.9 \%$ & $37.0 \%$ & $57.1 \%$ & \\
\hline \multirow[t]{2}{*}{ Total } & 29 & 27 & 56 & \\
\hline & $100.0 \%$ & $100.0 \%$ & $100.0 \%$ & \\
\hline
\end{tabular}




\section{Cureus}

\begin{tabular}{|c|c|c|c|c|}
\hline \multirow{2}{*}{ Transient Hypoparathyroidism } & \multicolumn{2}{|c|}{ Study groups } & \multirow{2}{*}{ Total } & \multirow{2}{*}{ p-value chi-square } \\
\hline & $\mathrm{FIO}_{2} 80 \%$ & $\mathrm{FIO}_{2} 30 \%$ & & \\
\hline \multirow{2}{*}{ Present } & 1 & 6 & 7 & \multirow{6}{*}{0.045} \\
\hline & $10.0 \%$ & $50.0 \%$ & $31.8 \%$ & \\
\hline \multirow{2}{*}{ Absent } & 9 & 6 & 15 & \\
\hline & $90.0 \%$ & $50.0 \%$ & $68.2 \%$ & \\
\hline \multirow[t]{2}{*}{ Total } & 10 & 12 & 22 & \\
\hline & $100.0 \%$ & $100.0 \%$ & $100.0 \%$ & \\
\hline
\end{tabular}

TABLE 8: Age-based stratification in both groups (51-75 years)

\section{Discussion}

The parathyroid glands lie in close proximity to the thyroid gland, however, they function independently. Identification and preservation of the parathyroid glands are essential during thyroidectomy. Knowledge of surgical anatomy is important for the identification of parathyroid glands during thyroid dissection. Parathyroid glands should not be removed during thyroid surgery unless they are grossly invaded by a thyroid malignancy or become severely ischemic during dissection. Transient hypoparathyroidism has been reported in 0.3 to 49 percent of patients after a thyroidectomy; up to 13 percent of post-thyroidectomy hypoparathyroidism becomes permanent. The risk of permanent hypoparathyroidism after a total thyroidectomy by an experienced surgeon has been reported as around two percent. It has been reported that high-concentration supplemental perioperative oxygen prevents the vasospasm and thus hypoxia, decreasing the incidence of biochemical hypoparathyroidism after thyroid surgery. In this study, we aimed to compare the effect of high concentration supplemental perioperative oxygen (80\%) with that of low concentration supplemental perioperative oxygen (30\%) on the frequency of transient biochemical hypoparathyroidism in patients undergoing total thyroidectomy.

A total of 78 patients between the ages of 18 and 75 years, irrespective of gender, undergoing elective thyroid surgery (total thyroidectomy were enrolled in the study. All the patients were equally distributed to two groups. Group 1 received $\mathrm{FiO}_{2} 80 \%$ while Group 2 received $\mathrm{FiO}_{2} 30 \%$ during the operation and six hours after the operation via an inbreathing face mask. Serum calcium at 24,48 , and 72 hours was estimated in each patient of both the groups. Our results showed that transient hypoparathyroidism was present in $20.5 \%(\mathrm{n}=8 / 39)$ in Group 1 while it was present in $59.0 \%(n=23 / 39)$ in Group 2 patients $(\mathrm{P}=0.001)$. Age- and gender-based stratification showed similar trends $(\mathrm{P}<0.05)$.

Available evidence on the effects of a high fraction of inspired oxygen $\left(\mathrm{FiO}_{2}\right)$ of $60 \%$ to $90 \%$, compared with a routine fraction of inspired oxygen of 30\% to $40 \%$, during anesthesia and surgery has been reported but is inconclusive. Previous trials and meta-analyses have led to different conclusions on whether a high fraction of supplemental inspired oxygen during anesthesia may decrease or increase mortality and surgical site infections in surgical patients 
[11]. Our results are similar to those reported by Schietroma M et al, who, in their study, showed that high-concentration supplemental perioperative oxygen during thyroid surgery and for six postoperative hours is effective in reducing postoperative transient biochemical hypoparathyroidism. It occurred less frequently with high concentration supplemental perioperative oxygen group $\left(\mathrm{FiO}_{2} 80 \%\right.$ ), i.e., $16.3 \%$ (20.5\% in the present study) compared to the control group (those receiving low supplemental perioperative oxygen $\mathrm{FiO}_{2} 30 \%$ ), i.e., $48.5 \%$

( $59 \%$ in the present study). The possible mechanism by which high-concentration supplemental perioperative oxygen decreases the incidence of biochemical hypoparathyroidism is by preventing vasospasms and thus hypoxia.

In summary, supplemental perioperative oxygenation is a low-cost intervention and its use during anesthesia and surgery has been reported. The data is inconclusive because of the heterogeneity in study designs and patient populations. The present study demonstrated the beneficial effects of supplemental oxygenation in patients who underwent elective thyroid surgery in terms of reducing the transient hypoparathyroidism rate. We did not find many studies on the effects of supplemental oxygenation on transient hypoparathyroidism after elective thyroid surgery. Nonetheless, it has been found beneficial in reducing surgical site infection. Further research is needed to define its clinical role.

\section{Conclusions}

Patients who received high concentration perioperative supplemental oxygen $\left(\mathrm{FiO}_{2} 80 \%\right)$ demonstrated a significantly lower percentage of transient hypoparathyroidism than those who received a lower concentration $\left(\mathrm{FiO}_{2} 30 \%\right)$. Similar trends were observed after age- and genderbased stratification.

\section{Additional Information}

\section{Disclosures}

Human subjects: Consent was obtained by all participants in this study. Rawalpindi Medical College and Allied Hospital, Rawalpindi issued approval R-01/RMC/. Animal subjects: All authors have confirmed that this study did not involve animal subjects or tissue. Conflicts of interest: In compliance with the ICMJE uniform disclosure form, all authors declare the following: Payment/services info: All authors have declared that no financial support was received from any organization for the submitted work. Financial relationships: All authors have declared that they have no financial relationships at present or within the previous three years with any organizations that might have an interest in the submitted work. Other relationships: All authors have declared that there are no other relationships or activities that could appear to have influenced the submitted work.

\section{References}

1. Schietroma M, Cecilia EM, Carlei F, Sista F, De Santis G, LancioneL, Amicucci G: Dexamethasone for the prevention of recurrent laryngeal nerve palsy and other complications after thyroid surgery: a randomized double-blind placebo-controlled trial. JAMA Otolaryngol Head Neck Surg. 2013, 139:471-478. 10.1001/jamaoto.2013.2821

2. Jialei $\mathrm{Gu}$, Jiafeng Wang, Xilin Nie, Wendong Wang, Jinbiao Shang: Potential role for carbon nanoparticles identification and preservation in situ of parathyroid glands during total thyroidectomy and central compartment node dissection. Int J Clin Exp Med. 2015, 8:96409648. Accessed: June 15, 2015: http://www.ncbi.nlm.nih.gov/pmc/articles/PMC4538139/.

3. Paek SH, Lee YM, Min SY, Kim SW, Chung KW, Youn YK: Risk factors of hypoparathyroidism following total thyroidectomy for thyroid cancer. World J Surg. 2013, 37:94-101. 10.1007/s00268-012-1809-4

4. Nawrot I, Pragacz A, Pragacz K, Grzesiuk W, Barczyński M: Total thyroidectomy is associated 
with increased prevalence of permanent hypoparathyroidism. Med Sci Monit. 2014, 20:16751681. 10.12659/MSM.890988

5. Sebastian H, François B, Andreas K, Peter R, Pierre A: Hyperoxia in intensive care, emergency, and peri-operative medicine: Dr. Jekyll or Mr. Hyde? A 2015 update. Ann Intensive Care. 2015, 5:42. Accessed: October 10, 2018: 10.1186/s13613-015-0084-6

6. Canet J, Belda FJ: Perioperative hyperoxia: the debate is only getting started. Anesthesiology. 2011, 114:1271-1273. 10.1097/ALN.0b013e31821bdbb5

7. Habre W, Peták F: Perioperative use of oxygen: variabilities across age . Br J Anaesth. 2014, 113:26-36. 10.1093/bja/aeu380

8. Beasley R, Chien J, Douglas J, et al.: Thoracic Society of Australia and New Zealand oxygen guidelines for acute oxygen use in adults: 'swimming between the flags'. Respirology. 2015, 20:1182-1191. 10.1111/resp.12620

9. Schietroma M, Piccione F, Cecilia EM, Carlei F, De Santis G, Sista F, Amicucci G: How does high-concentration supplemental perioperative oxygen influence surgical outcomes after thyroid surgery? A prospective, randomized, double-blind, controlled, monocentric trial. Respirology. 2015, 220:921-933 (Retracted). 10.1016/j.jamcollsurg.2015.01.046

10. Schietroma M, Cecilia EM, Sista F, Carlei F, Pessia B, Amicucci G: High-concentration supplemental perioperative oxygen and surgical site infection following elective colorectal surgery for rectal cancer: a prospective, randomized, double-blind, controlled, single-site trial. Am J Surg. 2014, 208:719-726 (Retracted). 10.1016/j.amjsurg.2014.04.002

11. Wetterslev J, Meyhoff CS, Jørgensen LN, Gluud C, Lindschou J, Rasmussen LS: The effects of high perioperative inspiratory oxygen fraction for adult surgical patients. Cochrane Database Syst Rev. 2015, 25:719-726. 10.1002/14651858.CD008884.pub2 